\title{
AÇÕES AUTÔNOMAS DE IMPUGNAÇÃO: AÇÃO RESCISÓRIA E QUERELA NULLITATIS INSANABILIS
}

ODETE BATISTA DIAS ALMEIDA 


\title{
AÇÕES AUTÔNOMAS DE IMPUGNAÇÃO: AÇÃO RESCISÓRIA E QUERELA NULLITATIS INSANABILIS
}

\author{
Odete Batista Dias Almeida ${ }^{1}$
}

\section{RESUMO:}

Em regra, a coisa julgada material é imutável, podendo sofrer relativização em determinadas circunstâncias específicas previstas na legislação e jurisprudência brasileiras. Neste particular, destaca-se a Ação Rescisória como procedimento largamente conhecido e hábil a combater a coisa julgada decorrente de uma nulidade, utilizada no campo do direito observadas as regras próprias de procedimento. De outro norte e buscando combater os vícios de inexistência, em especial por afronta a preceitos constitucionais, mencione-se o manejo da Ação Declaratória de Nulidade (Querela Nullitatis Insanabilis), a qual pressupõe a identificação de vícios que atinjam a própria declaração de existência, ou não, do ato impugnado, cuja vertente é interessante e integra o objeto deste escrito, na forma singela que se apresenta.

Palavras-chave: Ação Autônoma. Coisa Julgada Material. Nulidades. Inexistência.

\section{ABSTRACT:}

As a rule, the material res judicata is immutable and may undergo

\footnotetext{
1 Juíza Substituta respondendo pela 1ªra . Vável da Comarca de Gurupi/TO. Exerceu a advocacia empresarial por 15 (quinze) anos. Pós-Graduada em Direito Comercial (1999) e Direito Processual Civil (1997) pela Universidade Federal de Uberlândia (UFU). Exerceu a docência como titular da cadeira de Processo Civil e Prática Jurídica na Faculdade Objetivo (Rio Verde/GO). Lecionou Direito Processual Civil, Direito Civil e História do Direito na Faculdade Almeida Rodrigues (Rio Verde/GO). Ministrou aulas de Processo Civil no Instituto $\mathrm{n}^{\circ}$. 1 (Preparatório Para Concursos Públicos - Rio Verde/GO). Ministrou Cursos de Atualização Jurídica (Direito Constitucional) para professores universitários e acadêmicos de direito em Rio Verde-GO. Ministrou curso preparatório para o exame da OAB. Colaboradora da Revista "OAB in Foco" - Seccional de Uberlândia-MG (Revistas de nº. 20, 15 e 12), com os artigos: "Ativismo Judicial: Uma Moderna Tendência no STF"; "Controle Abstrativizado da Declaração de Inconstitucionalidade do $\S 1^{\circ}$. do Artigo $2^{\circ}$. da Lei de Crimes Hediondos" e "Improbidade Administrativa e o STF". Colaborou com a Revista Esmat de n'. 02 com o artigo "As Ações Possessórias e os Capitulos da Sentença”. Email: odetealmeida@tjto.jus.br
} 
relativization in determined circumstances provided for in Brazilian law and jurisprudence. In this particular, there is the Rescinding Legal Suit, one type of procedure able to combat the res judicata from a nullity, with the observance of own rules of procedure. On the other side and trying to combat the vices of existence, especially if it to configured an insult to the constitutional precepts, there is the Declaratory Claim of Nullity (Querela Nullitatis Insanabilis), that says about the localization of the vices that reaches de own existence declaration, or not, about the contested act, which is interesting and is part of the object of this writing, in the simple form that it presents.

Keywords: Autonomous Action. Material Res Judicata. Nullity. Absence.

\section{INTRODUÇÃO}

Para cuidarmos das ações autônomas de impugnação, , mister se faz mencionarmos sobre a coisa julgada, a bem da fidedigna percepção do alcance desta no tema a ser tratado.

Deste modo, sabido é que a coisa julgada é instituto consagrado de ordem constitucional inconteste, definido na Carta Magna $^{2}$ e assim considerado como efeito da sentença que busca trazer à sociedade a garantia da segurança jurídica, aliada ao ato jurídico perfeito e ao direito adquirido (Tríade da Segurança Jurídica).

Também se vislumbra o conceito de coisa julgada disposto na Lei de Introdução ao Código Civil Brasileiro (Decreto-Lei ${ }^{\circ}$. 4.657/42), sendo que: "chama-se coisa julgada ou caso julgado a

2 Artigo $5^{\circ}$. XXXVI - a lei não prejudicará o direito adquirido, o ato jurídico perfeito e a coisa julgada. 
decisão judicial de que já não caiba recurso"”.

Como complemento da dôtrina, diz-se que a coisa julgada é a imutabilidade decorrente da sentença de mérito que impede a sua discussão posterior.

Nesta linha e como uma primeira concepção, Pontes de Miranda e Ovídio Baptista da Silva ${ }^{4}$ consideram que a coisa julgada é um efeito da sentença que a torna indiscutível e imutável, compreendendo um efeito declaratório da sentença. Como segunda concepção, Enrico Tullio Liebman (adotada pelo Código de Processo Civil Brasileiro $)^{5}$ preconiza que a coisa julgada representa uma qualidade dos efeitos da sentença que a torna imutável, ou seja, é a própria indiscutibilidade dos efeitos desta. Ainda e como terceira concepção, Barbosa Moreira ${ }^{6}$ estabelece que a coisa julgada representa uma qualidade do conteúdo da sentença e não dos seus efeitos, sendo, destarte, a indiscutibilidade do conteúdo da sentença, ou seja, da própria decisão em si.

$\mathrm{Na}$ doutrina do mestre Marinoni ${ }^{7}$ :

A eficácia da sentença é a potencialidade (virtualidade)

$3 \quad$ Art. $6^{\circ}, \$ 2^{\circ}$.

4 SILVA, Ovidio A. Baptista da. Comentários ao Código de Processo Civil, Sentença e Coisa Julgada, São Paulo: Editora Revista dos Tribunais, 2000, p. 210.

$5 \quad$ Art. 467 - Denomina-se coisa julgada material a eficácia, que torna imutável e indiscutivel a sentença, não mais sujeita a recurso ordinário ou extraordinário. VadeMecum Saraiva, $11^{3}$. Edição, 2011 , p. 452.

6 BARBOSA MOREIRA, José Carlos. "Ainda e sempre a coisa julgada". In Direito Processual Civil. Rio de Janeiro: Borsoi, 1971, n. 3, p. 135-136.

7 MARINONI, Luiz Guilherme e ARENAHRT, Sérgio Cruz. Manual do Processo de Conhecimento. São Paulo: Editora Revista dos Tribunais, 2005, p. 616. 
que lhe é atribuida para produzir efeitos. Toda sentença, porque deve (ou ao menos pode) corresponder à pretensão de direito material exposta pelo autor, deve conter, em si, eficácias capazes de corresponder àquela pretensão e, assim, exercer a ação de direito material buscada. O conjunto dessas eficácias, somado a alguns efeitos (que ocorrem concomitantemente com a sentença), conforma aquilo que se denomina de conteúdo da sentença. E, ao se realizarem concretamente, essas eficácias convertem-se em efeitos concretos (sendo que esse momento pode ou não ocorrer instantaneamente com a prolação da sentença). Grifos conforme o original.

Neste sentido, diz-se que a coisa julgada é formal quando ocorrer a impossibilidade de se impugnar a sentença, não mais sujeita a recurso ou à remessa necessária dentro do processo em que foi proferida, ou seja, representa a impossibilidade de " se praticar um ato processual com efeitos limitados ao próprio processo.

Os efeitos são, portanto, endoprocessuais, significando que se vinculam à impossibilidade de rediscussão do tema decidido dentro da relação processual outrora perpetrada, podendo ocorrer nas decisões de ordem meramente processual. Guarda direta relação com o instituto da preclusão que, por sua vez, significa a extinção de uma faculdade processual, operada internamente à relação processual. Esgotados os recursos previstos legalmente por força da preclusão, verifica-se a ocorrência da coisa julgada formal.

Por sua vez, diz-se que a coisa julgada é material quando há a impossibilidade de rediscussão da matéria-objeto de decisão 
judicial - fora do processo, ou seja, sem qualquer possibilidade de análise em outra relação jurídica que porventura venha a se firmar. Nesta vertente, os efeitos da coisa julgada material se perpetuam extraprocessualmente, sendo referida circunstância de relevância imperiosa no mundo jurídico em geral.

Em regra, portanto, a coisa julgada material corresponde a toda coisa julgada, incluindo a coisa julgada formal, haja vista que alcança os efeitos endo e extraprocessuais. Na coisa julgada material, o julgamento torna-se regra imutável para a situação litigiosa que foi solucionada, estando os litigantes vinculados à decisão perpetrada, corroborada também pela vinculação do Poder Judiciário.

Neste diapasão, preceitua o artigo 468 do Código de Processo Civil Brasileiro que: "a sentença que julgar total ou parcialmente a lide tem força de lei nos limites da lide e das questões decididas". Em interpretação ao artigo citado, digase que, quando a decisão faz coisa julgada, a relação jurídica decidida passa a ser regida pela disposição emanada da sentença, ainda que referida decisão seja eventualmente contrária à lei.

Como efeitos da coisa julgada, temos:

a) o efeito negativo, vez que impede uma nova apreciação daquilo que já foi decidido no processo;

b) o efeito positivo, posto que se acaso vier a ser utilizada como fundamento de um novo processo, o juiz da causa estará obrigatoriamente vinculado à decisão que já tenha transitado em julgado;

c) o efeito da eficácia preclusiva da coisa julgada (artigo 
474 do Código de Processo Civil Brasileiro), que significa dizer que se tornam irrelevantes quaisquer alegações que poderiam ter sido realizadas e não o foram, ao tempo específico de análise do primeiro processo.

Como fundamento da coisa julgada, por certo que vige a necessidade de estabilização inerente às relações jurídicas. Proferida a sentença e esgotadas todas as hipóteses de revisão da mesma, é patente que as partes esperam, independentemente do resultado, o efeito da segurança jurídica previsto no texto constitucional.

Conforme dito alhures, a imutabilidade decorrente da coisa julgada é garantia constitucional devidamente expressa no artigo $5^{\circ}$., inciso XXXVI da Carta Magna, aliada ao direito adquirido e ao ato jurídico perfeito, o que deve ser observado a " bem do Estado Democrático de Direito em que vivemos (tríade constitucional que norteia a segurança jurídica).

A princípio, a coisa julgada confere à decisão proferida o status de imutabilidade. Neste contexto, afirme-se que a observância dos princípios insertos na Constituição Federal é pressuposto de validade de todo e qualquer ato jurídico, culminando, destarte, em questão de fundamental importância no tocante ao pressuposto da segurança jurídica que outrora buscou o legislador constituinte preservar.

Outrossim e não obstante, ocorre que, em hipóteses especiais, para não se dizer, especialíssimas, pode a coisa julgada estar eivada de algum vício, o qual somente foi verificado posteriormente ao trânsito em julgado da decisão referida - vício 
este que poderá estar em confronto, por exemplo, com outros princípios também de cunho constitucional e que redundam, por sua vez, na perpetuação de grave injustiça, cujo escopo não é aquele buscado pelo Poder Judiciário pátrio.

Em se verificando a circunstância acima mencionada, é fato que a coisa julgada no contexto inferido pode ser atacada por Ação Rescisória ou ainda pela propositura de Ação Autônoma Declaratória de Inexistência - Querela Nullitatis Insanabilis, além da oposição de Embargos à Execução pautados no parágrafo único do artigo 741 do Código de Processo Civil Brasileiro e Impugnação de Sentença fundada no $\S 1^{\circ}$. do artigo 475-L do mesmo diploma legal.

\section{DA AÇÃO RESCISÓRIA}

A Ação Rescisória possui previsão no ordenamento jurídico brasileiro no artigo 485 do Código de Processo Civil Brasileiro, cujo rol é taxativo e representa numerus clausus, tendo como finalidade a desconstituição de sentenças de mérito que tenham transitado em julgado e perpetuado a coisa julgada material que padeça, porém, de algum vício flagrante e grave hábil a culminar na nulidade, podendo ser proposta no prazo de até 02 (dois) anos após o trânsito em julgado da decisão.

Não é recurso, uma vez que não atende ao Princípio da Taxatividade. Ainda, é certo que os recursos não formam outro processo ou sequer instauram uma nova relação jurídica processual, como é o caso da Ação Rescisória. Em resumo, 
ressalte-se que as ações autônomas de impugnação geram novo processo e possuem a natureza jurídica de ação constitutiva negativa ou desconstitutiva, a depender do comando atacado.

As hipóteses de rescindibilidade estão previstas no artigo 485 do Código de Processo Civil Brasileiro, sendo, conforme dito acima, de fundamentação vinculada ou típica, com causa de pedir restrita e rol taxativo. Por certo que qualquer inciso é suficiente para a pretensão de rescindir e, uma vez alegadas várias hipóteses, ocorre a cumulação da causa de pedir, funcionando o pedido como se fossem várias rescisórias constantes de uma mesma peça de ingresso, sendo que o Judiciário somente pode decidir com base nas causas de pedir deduzidas.

\subsection{Do Cabimento}

Sabido é que a Ação Rescisória serve para desfazer a coisa julgada em seu aspecto amplo, seja por motivos de invalidade (artigo 485, II e IV do CPC) ou por motivos de injustiça (artigo 485, VI e IX do CPC). Entretanto, a Ação Rescisória não é passível de manejo:

a) contra as sentenças proferidas nos Juizados Especiais (artigo 59 da Lei 9.099/95);

b) contra as decisões proferidas nas Ações de Controle de Constitucionalidade (Ação Declaratória de Inconstitucionalidade - ADIN; Ação Declaratória de Constitucionalidade - ADECON - artigo 26 da Lei 9.868/99 e Ação Declaratória de Preceito Fundamental - ADPF - artigo 12 da Lei 9.882/99); 


\section{sia}

c) no processo cautelar, à exceção da previsão contida no artigo 810 do Código de Processo Civil Brasileiro;

d) nos procedimentos de jurisdição voluntária.

De outro norte, é cabível contra a decisão interlocutória (desde que faça coisa julgada material) bem como contra a sentença proferida com base na renúncia, na transação, no reconhecimento do pedido, na confissão e, por fim, em desfavor das sentenças homologatórias.

Segundo o Supremo Tribunal Federal $(\mathrm{STF})^{8}$, cabe Ação Rescisória contra a sentença transitada em julgado, ainda que não se tenham esgotados todos os recursos cabíveis no caso concreto. Neste particular, traz-se à baila a controvérsia acerca do trânsito em julgado referente aos capítulos da sentença, cujo tema foi objeto de escrita em artigo publicado na Revista Esmat de $\mathrm{n}^{\circ} .2^{9}$, remetendo-se o leitor para aquela leitura.

\subsection{Das Generalidades}

Vale ponderar que a Fazenda Pública não dispõe de prazo em dobro para propor a Ação Rescisória, o que lhe é permitido apenas para contestar e recorrer (artigo 188 do CPC).

Com a pretensão alusiva, foi editada a Medida Provisória (MP) de $\mathrm{n}^{\circ}$ : $1.577 / 97$ que previa o prazo em dobro em favor da Fazenda, inclusive aumentando para 05 (cinco) anos o prazo para

\footnotetext{
$8 \quad$ Súmula 514

9 Revista Esmat, ISSN 2177 - 0360, Ano 2, $\mathrm{n}^{\circ} .2$, janeiro/dezembro 2010, p. 151.
} 
a propositura que se trata. Entretanto e em julgamento da Ação Declaratória de Inconstitucionalidade (ADIN) de $\mathrm{n}^{\circ}$. 1.753, o Supremo Tribunal Federal declarou a inconstitucionalidade das previsões respectivas, o que deve ser observado.

Como generalidades do manejo da Ação Rescisória, ressalte-se a necessidade de realização do depósito obrigatório previsto no artigo 488 do CPC, no importe de $5 \%$ (cinco por cento) do valor da causa que, no caso de improcedência ou inadmissibilidade, reverter-se-á ao requerido.

Ainda, cabe mencionar que a Medida Provisória (MP) de n ${ }^{\circ}$ 2180-35 dispensa a Caixa Econômica Federal (CEF) de realizar referido depósito em causas de discussão sobre o Fundo de Garantia por Tempo de Serviço (FGTS). Quanto ao prazo de resposta, uma peculiaridade é que o mesmo é flexível, sendo 'de competência do relator fixá-lo entre 15 (quinze) a 30 (trinta) dias, lembrando que referido prazo, mesmo para litisconsortes com procuradores diferentes, não é computado em dobro, pois que o artigo 188 do CPC cuida dos prazos legais, sendo este um prazo judicial, alheio, portanto, àquela previsão.

Também pode ocorrer a revelia no feito em comento (artigo 319 do CPC), porém, sem a aplicação da confissão ficta por enfrentar o tema a autoridade da coisa julgada.

A reconvenção é possível, desde que também o seja na modalidade de outra Ação Rescisória e contra o mesmo julgado, não existindo as figuras dos recursos de Agravo Retido e sequer de Apelação. Também é possível o manejo de ação rescisória contra a própria rescisória (Súmula 400 do Tribunal Superior 
do Trabalho - TST), com fundamento no acórdão da rescisória e não no acórdão da decisão origináría.

Apesar do rol taxativo contido no artigo 485 do CPC, é possível a propositura de Ação Rescisória com base no artigo 1.030 do diploma legal acima citado, isto contra a sentença que julgar a partilha de bens.

\section{DA QUERELA NULLITATIS INSANABILIS}

A Ação Declaratória de Inexistência tem pressuposto na assertiva de que as sentenças que se consubstanciaram em leis inconstitucionais ou que recusaram a aplicação de leis constitucionais, sob o argumento da inconstitucionalidade, seriam sentenças inexistentes, não tendo o condão de fazer coisa julgada.

Nesta esteira de pensamento podemos citar a doutrina de Tereza Arruda Alvim Wambier ${ }^{10}$ como expoente de peso na ordem jurídica pátria. Para a referida autora, os vícios das sentenças podem ser classificados como sendo de nulidade ou de inexistência.

No dizer da autora e para a ação judicial "existente", o caminho jurídico seria a impugnação via Recurso ou Ação Rescisória. Por sua veze para os vícios intitulados transrescisórios (para processos com sentenças inexistentes ou nulas), o percurso seria a propositura da chamada Ação de Nulidade (Querela

10 WAMBIER, Tereza Arruda Alvim. Nulidades do Processo e da Sentença. 4a. ed. RT. São Paulo: 1997 
Nullitatis), a exemplo da verificação de uma nulidade decorrente da não observação dos pressupostos processuais (como a ausência de citação válida e posterior decretação da revelia) ou mesmo das condições da ação.

Assim, as sentenças padeceriam de vício de nulidade:

a) quando apresentassem vícios intrínsecos, quais sejam: o desatendimento ao Princípio da Congruência (sentenças citra petita, ultra petita ou extra petita);

b) quando provenientes de processo onde tenha havido nulidades flagrantes (vícios extrínsecos) e outros casos, como por exemplo, as disposições contidas no artigo 485, VII do Código de Processo Civil Brasileiro.

No tocante à anulabilidade e no dizer da renomada autora indicada, não existiriam sentenças anuláveis, considerando que " eventual vício desta natureza que porventura tenha surgido no curso do processo restaria superado pelo instituto da própria preclusão.

Nesta linha, afirma a autora em referência que as sentenças nulas podem ser desconstituídas através da propositura de Ação Rescisória, ao passo que as sentenças "inexistentes", oriundas dos vícios formais absolutos, jamais poderiam fazer coisa julgada, pelo que e para desconstituir o que não existe, a declaração da referida inexistência pode ser feita a qualquer tempo e por via da intitulada Ação Declaratória de Inexistência, conhecida também como Querela Nullitatis Insanabilis. 


\section{Segundo Antônio Pereira Gaio Júnior11:}

Dentre o universo de atos processuais, sabido é que a citação tem significado fundamental, sobretudo, no Estado Democrático de Direito, dado encarnar a própria garantia do contraditório, sendo que o réu, ao ser citado validamente, repercute não somente na formação integral da relação processual bem como oportuniza ao próprio demandado o conhecimento exato da pretensão face a ele reclamada, além da incidência de todo aquele rol de efeitos ditados pelo art. 219 do CPC. Assim, pelo acima dito, uma vez realizando-se tal ato de comunicação e permanecendo o réu inerte quanto à apresentação de sua peça contestatória, darse-á a incidência da revelia em sentido estrito cujos efeitos desta, inegavelmente, serão danosos ao réu. Ocorre que tal citação pode estar eivada de vício (falta ou nulidade), implicando, ainda que do silêncio e inércia do réu, ofensa ao direito sublime de ser citado. Ocorre que tal citação pode estar eivada de vício (falta ou nulidade) implicando, ainda que do silêncio e inércia do réu, ofensa ao direito sublime de ser citado. O defeito em questão, realmente, é de grande repercussão de modo que sua problemática envolve a perspectiva de ataque à sentença proferida em processo no qual foi a citação omitida, ou, se realizada, configurou-se nula, levando-se ainda assim o réu à condição de revel, salvo, evidentemente, as escusas contidas nos $\S \S 1^{\circ}$ e $2^{\circ}$ do art. 214 do CPC. Para o enfrentamento de inescrupulosa sentença, têm doutrina e jurisprudência se esmerado para a defesa no tocante à subsistência da chamada querela nullitatis. Grifamos.

Também o Superior Tribunal de Justiça (STJ), em recente decisão, assevera que a ausência de citação conduz à propositura

11 Disponivel em http://www.editoramagister.com. In A Efetiva Aplicabilidade da Querela Nullitatis,acesso na data de 25/3/2009 
da Querella Nullitatis. Vejamos:

PROCESSUALCIVIL.EMBARGOSDEDECLARAÇÃO. OMISSÃO VERIFICADA. AÇÃO RESCISÓRIA. AUSÊNCIA DE CITAÇÃO DE LITISCONSORTE PASSIVO NECESSÁRIO. HIPÓTESE DE QUERELLA NULITATIS. APRECIAÇÃO DOS PRINCÍPIOS DA FUNGIBILIDADE, DA INSTRUMENTALIDADE DAS FORMAS, CELERIDADE E ECONOMIA PROCESSUAIS. 1. Ao extinguir a presente ação rescisória sem resolução de mérito, o acórdão ora embargado fundou-se no não cabimento de ação rescisória para declarar nulidade de julgado por ausência de citação, considerando que a hipótese dos autos não se enquadra no rol taxativo do art. 485 do CPC. Decidiu-se, assim, que a desconstituição do acórdão proferido nos autos do Recurso Especial n. 8.818/PE somente poderia ser postulada pelo autor por meio de ação declaratória de inexistência de citação, denominada querela nullitatis. 2 . Verificada a omissão do julgado quanto à aplicação dos princípios da instrumentalidade das formas, da celeridade e economias processuais. 3 . Não está autorizada a aplicação dos princípios que norteiam o sistema de nulidades no direito brasileiro, em especial os da fungibilidade, da instrumentalidade das formas e do aproveitamento racional dos atos processuais, para que a rescisória seja convertida em ação declaratória de inexistência de citação, máxime quando inexiste competência originária do Superior Tribunal de Justiça para apreciar aquela ação cognominada querela nullitatis. Isto porque a Constituição Federal apenas autoriza o processamento da inicial diretamente perante esta Corte Superior nas hipótese expressamente delineadas em seu art. 105, inciso I. 4. Por outro lado, é assente a orientação do Superior Tribunal de Justiça no sentido de que a competência para apreciar e julgar a denominada querela nullitatis Insanabilis pertence ao juízo de primeira instância, pois o que se postula não é a desconstituição da 
coisa julgada, mas apenas o reconhecimento de inexistência da relação processual. Neste sentido, são os seguintes julgados: AgRg no REsp 1199335 / RJ, Primeira Turma, rel. Benedito Gonçalves, DJe 22/03/2011; REsp 1015133/ MT, Segunda Turma, Rel. Ministra Eliana Calmon, Rel. p/ Acórdão Ministro Castro Meira, DJe 23/04/2010; REsp 710.599/SP, Primeira Turma, Rel. Ministra Denise Arruda, DJ 14/02/2008. 5.Embargos de declaração acolhidos, sem efeitos infringentes. (EDcl na AR .569/PE, Rel. Ministro MAURO CAMPBELL MARQUES, PRIMEIRA SEÇÃO, julgado em 22/06/2011, DJe 05/08/2011). Grifamos.

\subsection{Previsões e Generalidades}

No direito brasileiro, a Querela Nullitatis está prevista como hipótese de cabimento de impugnação à execução de sentença (artigo 475-L, I, CPC) e como hipótese de cabimento dos Embargos à Execução contra a Fazenda Pública (artigo 741, I, CPC), podendo, entretanto, assumir a feição de outro procedimento, a exemplo da ação autônoma de invalidação da decisão judicial.

A Ação Declaratória de Inexistência ou de Nulidade Insanável - Querela Nullitatis Insanabilis - está revivendo em nosso ordenamento jurídico, posto que, em se verificando a coisa julgada considerada inconstitucional, a referida ação possui o condão de declarar a nulidade do julgado sem demais formalidades.

Assim, a Querela Nullitatis Insanabilis é modalidade de ação autônoma de impugnação que almeja alcançar a declaração 
de existência de grave vício no comando judicial outrora transitado em julgado, a exemplo da ausência ou nulidade da citação válida que, para parte da doutrina, cuida não de simples nulidade, mas de franca inexistência do comando no mundo jurídico.

Pode ser manejada a qualquer tempo, sendo, pois, imprescritível, uma vez que um comando considerado inexistente assim o é por todo o tempo. Obedece tanto ao processo de conhecimento, especificamente nos ritos ordinário ou sumário, quanto ao processo executivo, imbuída da pretensão de ver declarada inexistente referida sentença que não tenha observado os vícios da natureza acima elencados.

Ressalte-se que o Superior Tribunal de Justiça (STJ) já admitiu a medida tanto em Ação Civil Pública quanto em "Exceção de Pré-Executividade, a qual, se relembre, é cabível tão-somente para matérias de ordem pública bem como aquelas que não dependam de instrução probatória.

O manejo da Ação Querela Nullitatis também é possível para os casos de relativização da coisa soberanamente julgada, isto para vícios constitucionais, aferidos após o prazo de 02 (dois) anos da Ação Rescisória.

Neste diapasão, alguns doutrinadores como Carlos Valder do Nascimento ${ }^{12}$, Cândido Rangel Dinamarco ${ }^{13}$ e Humberto

12 NASCIMENTO, Carlos Valder do. Coisa Julgada Inconstitucional. ed. América Jurídica. Rio de Janeiro: 2002. p. 124 e ss.

13 DINAMARCO, Cândido Rangel. Relativizar a Coisa Julgada Material. In NASCIMENTO. Op. Cit. p. 122 
Teodoro Júnior ${ }^{14}$ vêm apontando a possibilidade de, com a finalidade de desconstituir a coisa julgada inconstitucional, admitir-se o ajuizamento de uma ação autônoma, a qualquer tempo, como se pode verificar do trecho seguinte de Carlos Valder ${ }^{15}$ :

Não há como, pelo que se infere do exposto, convalidar sentença nula, notadamente contaminada pelo vício da inconstitucionalidade que não subordina sua desconstituição ao manejo da rescisória. De fato, essa é a regra que prevalece no direito brasileiro, o que possibilita a recorrer-se a ação de impugnação autônoma, tanto quanto a de incidentes de embargos à execução. Grifamos.

Para alguns, entretanto, a natureza jurídica da coisa julgada inconstitucional é um ato nulo e não inexistente, uma vez que a conceituação de ato inexistente corresponde ao ato desprovido dos caracteres mínimos de um ato judicial, podendo a nulidade apontada ser arguida tanto no prazo bienal da ação rescisória quanto a qualquer tempo, haja vista que a inconstitucionalidade não pode ser convalidada.

Para os defensores da Querela Nullitatis, poderá a parte rechaçar a coisa julgada mediante o fenômeno da relativização desta, passando a imutabilidade da sentença a ser combatida, desta vez, sem a necessidade, por exemplo, de interposição de ação rescisória.

14 JÚNIOR, Humberto Theodoro. A Coisa julgada Inconstitucional e os Instrumentos Processuais para seu Controle. In NASCIMENTO. Op. Cit.

15 Op. Cit. 
Fundamentam a hipótese em tela, por exemplo, quando se verifica flagrante conflito entre a coisa julgada e os princípios constitucionais que devem nortear toda e qualquer relação jurídica, decorrendo, então e por assim dizer, a relativização da coisa julgada posto a inobservância de outros princípios constitucionais, em especial, aqueles ligados à Isonomia, à Dignidade da Pessoa Humana e à Proporcionalidade.

Nesta linha, há a necessidade de se revisar a coisa julgada com fulcro no Princípio da Proporcionalidade ou da Razoabilidade, com o escopo de se ver redimida eventual injustiça que, porventura, tenha sido perpetrada em decisão judicial acobertada pelo manto da coisa julgada.

\section{CONSIDERAÇÕES FINAIS}

$\mathrm{O}$ direito vigente permite a desconstituição da coisa julgada acaso sejam verificadas as hipóteses da Ação Rescisória, sendo que, para vícios considerados transrescisórios, afetos à existência, ou não, do próprio ato impugnado, existe a possibilidade de manejo da chamada Querela Nullitatis, a fim de evidenciar o ataque ao comando judicial transitado em julgado que afronte os preceitos de ordem constitucional.

O intuito é evitar a perpetuação da coisa julgada considerada inconstitucional, ainda que após o advento da coisa soberanamente julgada, ou seja: após o decurso do prazo de 02 (dois) anos permissivos da Ação Rescisória, posto a afronta à Carta Magna e ao direito de implementação da prestação 
jurisdicional fidedigna, cujo anseio pertence à sociedade.

A relativização da coisa julgada consiste na avaliação do conflito que a coisa julgada inconstitucional representa face aos Princípios da Segurança Jurídica e a Supremacia da Constituição Federal sobre todos os atos jurídicos.

Assente então que, uma vez observada a inconstitucionalidade de uma decisão judicial transitada em julgado, todos os valores nesta envolvidos deverão ser objeto de confronto entre si, a fim de que se conclua, ou não, pela preservação da coisa julgada ou pela supremacia do Princípio constitucional porventura violado.

Acaso seja apurada a violação a determinado Princípio constitucional - violação esta que, no caso concreto, possa representar ofensa maior ao sistema jurídico como um todo, sendo maior que a segurança jurídica buscada pelo legislador constituinte - cogita-se, então, da relativização da coisa julgada mesmo após decorrido o prazo bienal da Ação Rescisória por meio da Querela Nullitatis, tudo como medida de imperativa justiça e a bem da manutenção do Estado Democrático de Direito vigente.

\section{REFERÊNCIAS BIBLIOGRÁFICAS}

BARBOSA MOREIRA, José Carlos. "Ainda e sempre a coisa julgada". In Direito Processual Civil. Rio de Janeiro: Borsoi, 1971. 
BRASIL. Supremo Tribunal Federal. Súmula 514.

BRASIL. Superior Tribunal de Justiça. EDcl na AR .569/ PE, Rel. Ministro Mauro Campbell Marques, primeira seção, julgado em 22/06/2011, DJe 05/08/2011.

DINAMARCO, Cândido Rangel. Relativizar a Coisa Julgada Material. In Coisa Julgada Inconstitucional. Rio de Janeiro: América Jurídica, 2002.

Gaio JR, Antônio Pereira. A Efetiva Aplicabilidade da Querela Nullitatis. Disponível em: http://www.editoramagister.com. Acesso em data de 25/3/2009.

" THEODORO JR., Humberto. ACoisa Julgada Inconstitucional e os Instrumentos Processuais para seu Controle. Revista de Direito Processual Civil. vol. 21.

LIEBMAN, Enrico Tullio. Eficácia e autoridade da sentença. Trad. Alfredo Bazaid e Benvindo Aires. Rio de Janeiro: Forense, 1945.

MARINONI, Luiz Guilherme e ARENHART, Sérgio Cruz. Manual do Processo de Conhecimento. São Paulo: RT, 2005.

NASCIMENTO, Carlos Valder do. Coisa Julgada Inconstitucional. Rio de Janeiro: América Jurídica, 2002. 
PONTES DE MIRANDA, Francisco Cavalcanti. Comentário ao Código de Processo Civil. Rio de Janeiro: Forense, 1976. vol. 9.

SILVA, Ovídio A. Baptista da. Comentários ao Código de Processo Civil, Sentença e Coisa Julgada. São Paulo: RT, 2000.

VADE Mecum, Código Civil, 11ª . ed. São Paulo: Saraiva, 2011.

VADE Mecum, Código de Processo Civil, 11ª ed. São Paulo: Saraiva, 2011.

VADE Mecum, Constituição Federal, $11^{\mathrm{a}}$. ed. São Paulo: Saraiva, 2011.

WAMBIER, Tereza Arruda Alvim. Nulidades do Processo e da Sentença. $4^{\text {a }}$. ed. São Paulo: RT, 1997. 